\title{
A FUZZY BASED LOAD SHEDDING SCHEME FOR AN ISLANDED DISTRIBUTION NETWORK
}

\author{
Hazlie Mokhlis ${ }^{\text {a, }}$, Javed Ahmed Leghari ${ }^{\text {a, b }}$, Ab Halim Abu Bakar ${ }^{\text {b }}$, \\ ${ }^{a}$ Department of Electrical Engineering, Faculty of Engineering, University of Malaya, 50603 Kuala Lumpur, Malaysia \\ bUMPEDAC, Level 4, Wisma R\&D University of Malaya, 59990 Kuala Lumpur, Malaysia \\ hazli@um.edu.my, javedahmedleghari@gmail.com, a.halim@um.edu.my
}

\begin{abstract}
A severe disturbance in a power system grid may lead to system blackout or network splitting. In this situation, an islanded distribution network can survive if it has effective load shedding scheme. However, the conventional load shedding technique may not work well to ensure the frequency remains stable in an islanded distribution network. Thus, efficient technique is required to respond fast in determining the accurate amount of load to be shed. This paper presents efficient load shedding strategy based on fuzzy logic for islanding operation of a distribution network and generator tripping in distribution network. The simulation results show that the proposed strategy satisfactorily stabilize the frequency during islanding operation and generator tripping events.
\end{abstract}

\section{KEY WORDS}

Islanding operation, load shedding, fuzzy logic

\section{Introduction}

Due to market deregulation and environmental constraints, the use of Distributed Generation (DG) resources has been widely employed in power industry [1]. The DG implementation has the advantage that it increases the reliability and efficiency of the power system networks and power utilities. Furthermore, it also provides economic benefits to the customer in term of Feed in Tariff [2]. However, its penetration in existing power system network causes some technical challenges that need to be addressed. One of the issues is operation of DG during islanded mode, in which DG is electrically isolated from the main grid. Without proper control this condition may result in severe disturbances leading to power blackout [3, 4].

To avoid blackout, load shedding techniques are commonly applied. The load shedding technique employs frequency relay to stabilize frequency under serious disturbances. The principle of this technique is based on the operation of under frequency relay when generator frequency drops below a certain threshold value. Conventional Under Frequency Load Shedding Scheme
(UFLS) shed a fixed amount of electrical power in fixed steps. This scheme is unreliable in shedding the optimal value of loads [3-6].

Since conventional load shedding scheme shed the load in fixed steps, it often shed more load than required. To address this issue, power swing equation is employed to estimate the amount of power imbalance by measuring frequency and rate of change of frequency of the system. Power swing equation after measuring these parameters estimates the amount of load to be shed to stabilize the frequency. The load shedding technique based on power swing equation is known as an adaptive UFLS technique.

Anderson and Mirheydar has presented an adaptive UFLS technique based on voltage variation principle to determine the most appropriate bus and shed the load of that bus [7]. Shokooh et al. proposed an adaptive UFLS technique to shed amount of load by measuring frequency, rate of change of frequency and change in voltage [8]. Jung et al. propose setting of under frequency relay to operate for load shedding is based on initial slope of rate of change of frequency [9]. These schemes can operate successfully, provided that grid is facilitated with high speed communication technology.

These UFLS scheme may not ensure system security when applied in a distribution network which is operating in islanded mode. This is due to the fact that system frequency severely disturbed during islanding mode. Also, DG system has smaller inertia which causes a fast drop of frequency. Hence, a DG system operating in islanded mode requires an appropriate adaptive load shedding scheme.

This paper presents a new UFLS technique by applying fuzzy logic control approach. The proposed strategy uses frequency, rate of change of frequency and load prioritization to shed the optimal value of loads. The proposed UFLS scheme is tested for islanding operation and generator tripping cases.

The paper is organised as follows; section 2 presents the proposed load shedding technique. Section 3 describes the test system to verify the effectiveness of the proposed 
technique. Section 4 presents two case studies, which involves with islanded operation and generator tripping. Finally Section 5 is the concluding remarks of the work.

\section{Methodology}

\subsection{Description of Proposed Scheme}

The proposed load shedding scheme uses fuzzy logic control approach to stabilize frequency by shedding correct amount of load. The scheme is consists of fuzzy based load shedding module (FBLSM) which estimates and shed the load in two steps. In the first step it receives the input frequency and $d f / d t$ from the DG units and monitors these values. Depending upon the values it estimates the power imbalance in the network. In the second step FBLSM sheds the estimated load according to load priority. The layout of the proposed UFLS technique is illustrated in Figure 1.

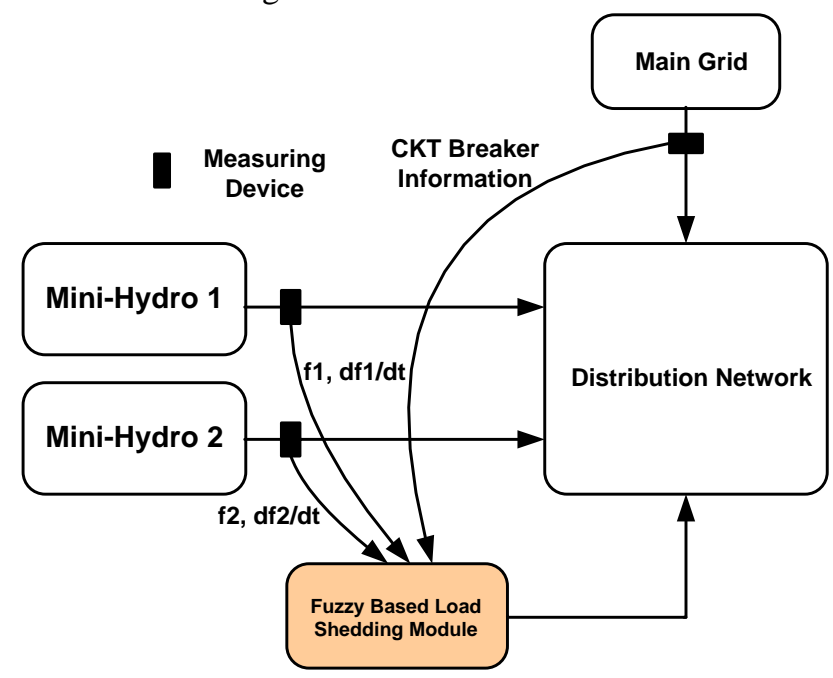

Figure 1. Proposed fuzzy based UFLS scheme layout

The TNB utility of Malaysia practices $49.5 \mathrm{~Hz}$ as a standard frequency to start load shedding [10]. The coordination of under-frequency protection of generator with under-frequency load shedding scheme is very important. If system frequency goes below certain threshold value, under frequency protection relay of generator will operate and system will collapse unnecessarily. The minimum allowed operating frequency usually specified by the manufacturer according to the type of turbine is $47.5 \mathrm{~Hz}$ [11].

\subsection{Modelling of Fuzzy Based Load Shedding Module}

Fuzzy based load shedding module (FBLSM) is modelled in PSCAD software. PSCAD is used as it is a powerful tool for studying the transient phenomenon in electrical power system networks [8]. The FBLSM is modelled in PSCAD by writing coding in C language since PSCAD does provide fuzzy logic tool box. FBLSM for UFLS scheme consists of two inputs (frequency $(f)$ and $(d f / d t)$ ) and one output (load shed). Depending upon the input values, FBLSM will estimates the power imbalance and determine the amount of load to shed and its block diagram is shown in Figure 2.

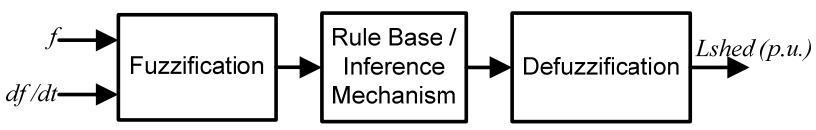

Figure 2.Fuzzy based load shedding Module block diagram

The first modelling step of FBLSM is fuzzification. In this step the actual input parameters are converted into fuzzy set parameters. The conversion process assigns a respected degree to each inputs parameters belonging to fuzzy parameters. This step is modelled in PSCAD by using equation of slope. Figure 3 show a membership function (Low) of input frequency and its sample coding is described in equations (1)-(4).

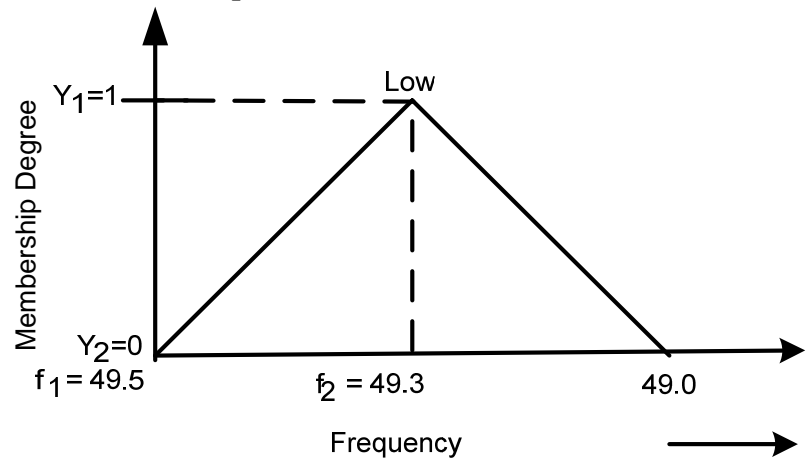

Figure 3. Fuzzification of frequency membership function

$$
\begin{aligned}
& \text { Slope Equation }=\frac{y-y_{1}}{x-x_{1}}=\frac{y_{2}-y_{1}}{x_{2}-x_{1}} \\
& \text { Slope }=\frac{y_{2}-y_{1}}{x_{2}-x_{1}} \\
& \frac{y_{2}-y_{1}}{f_{2}-f_{1}}=\frac{M . \text { degree }-y_{1}}{\text { frequency }-f_{1}} \\
& \text { M. degree }=\text { slope } \times\left(\text { frequency }-f_{1}\right)+y_{1}
\end{aligned}
$$

FBLSM input membership function are shown in Figure 4-5 whereas its output membership functions is shown in Figure 6. The second modelling step of FBLSM is fuzzy rule base and inference mechanism. The rule base helps FBLSM in making decisions for input and output control actions and is applied in IF-THEN rule whereas inference mechanism determines active signals to take control actions by using these rules. The example of rule base is given below: 
IF frequency is low and df/dt is HN THEN Load shed is Lshed.

IF frequency is Vextlow and df/dt is HN THEN Load shed is EXTHshed.

The rule table of FBLSM is shown in Table 1.
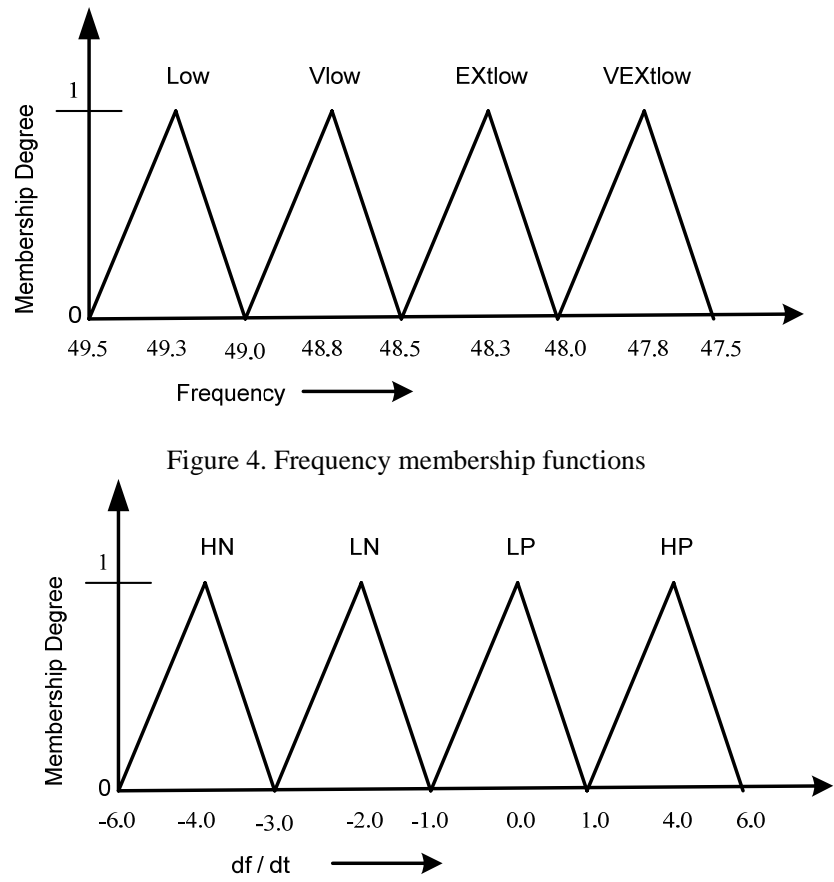

Figure 5. $d f / d t$ membership functions

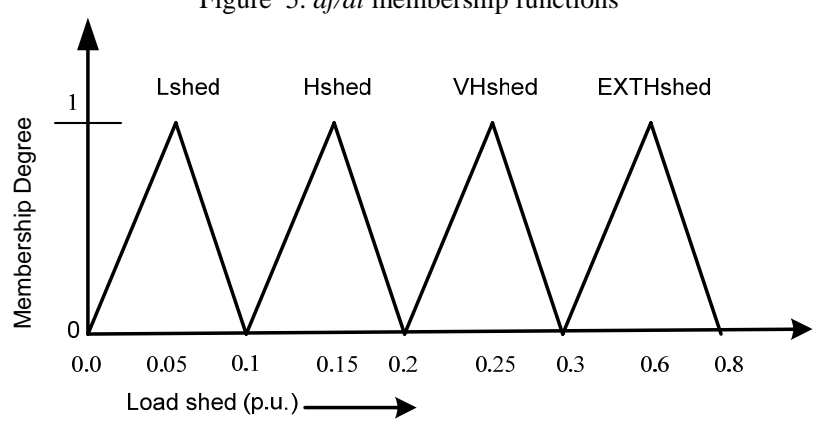

Figure 6. Load shed (p.u.) membership functions

Table 1

Fuzzy based load shedding module rule table

\begin{tabular}{|c|c|c|c|c|c|}
\hline & \multicolumn{4}{|c|}{ Frequency } \\
\hline & & Low & Vlow & Extlow & Vextlow \\
\hline \multirow{4}{*}{$\frac{\theta}{t}$} & $\mathrm{HN}$ & Lshed & VHshed & VHshed & EXTHshed \\
\hline & LN & Lshed & Lshed & VHshed & EXTHshed \\
\hline & LP & Hshed & Hshed & Lshed & Lshed \\
\hline & HP & Hshed & Hshed & Hshed & Hshed \\
\hline
\end{tabular}

The last modelling step of FBLSM is defuzzification. This step is used to convert the fuzzy values into real crisp values. In this model, weighted average method is used for defuzzification.

\section{Test System}

The test system for fuzzy based load shedding scheme is shown in Figure 7. The distribution network is supplied by two mini-hydro units. Each DG unit has 2 MVA (maximum power dispatch is $1.83 \mathrm{MW}$ ) capacity and is modelled in PSCAD/EMTDC software. Each node is connected with remote circuit breaker (RCB) that can be remotely controlled for load shedding purposes. The standard model for exciter, governor and hydraulic turbine provided in PSCAD/EMTDC library are used in this study. The distribution network has load profile and the power consumption of each load and its priority is shown in Table.2.

Table 2

Load Ranking Table

\begin{tabular}{|c|c|c|}
\hline \multirow{2}{*}{ Load priority } & \multicolumn{2}{|c|}{ Distribution Network Load Values } \\
\hline & $\mathrm{P}(\mathrm{MW})$ & O (MVAR) \\
\hline Load 1 & 0.0684 & 0.0423 \\
\hline Load 2 & 0.0795 & 0.0495 \\
\hline Load 3 & 0.0795 & 0.0495 \\
\hline Load 4 & 0.1095 & 0.0576 \\
\hline Load 5 & 0.1794 & 0.0792 \\
\hline Load 6 & 0.189 & 0.1152 \\
\hline Load 7 & 0.198 & 0.123 \\
\hline Load 8 & 0.234 & 0.1101 \\
\hline Load 9 & 0.1488 & 0.0867 \\
\hline Load 10 & 0.1743 & 0.108 \\
\hline Load 11 & 0.2097 & 0.1275 \\
\hline Load 12 & 0.2121 & 0.1314 \\
\hline Load 13 & 0.2535 & 0.1578 \\
\hline Load 14 & 0.2745 & 0.1716 \\
\hline Load 15 & 0.3468 & 0.2148 \\
\hline Load 16 & 0.1902 & 0.099 \\
\hline Load 17 & 0.2208 & 0.0996 \\
\hline Load 18 & 0.345 & 0.3282 \\
\hline
\end{tabular}




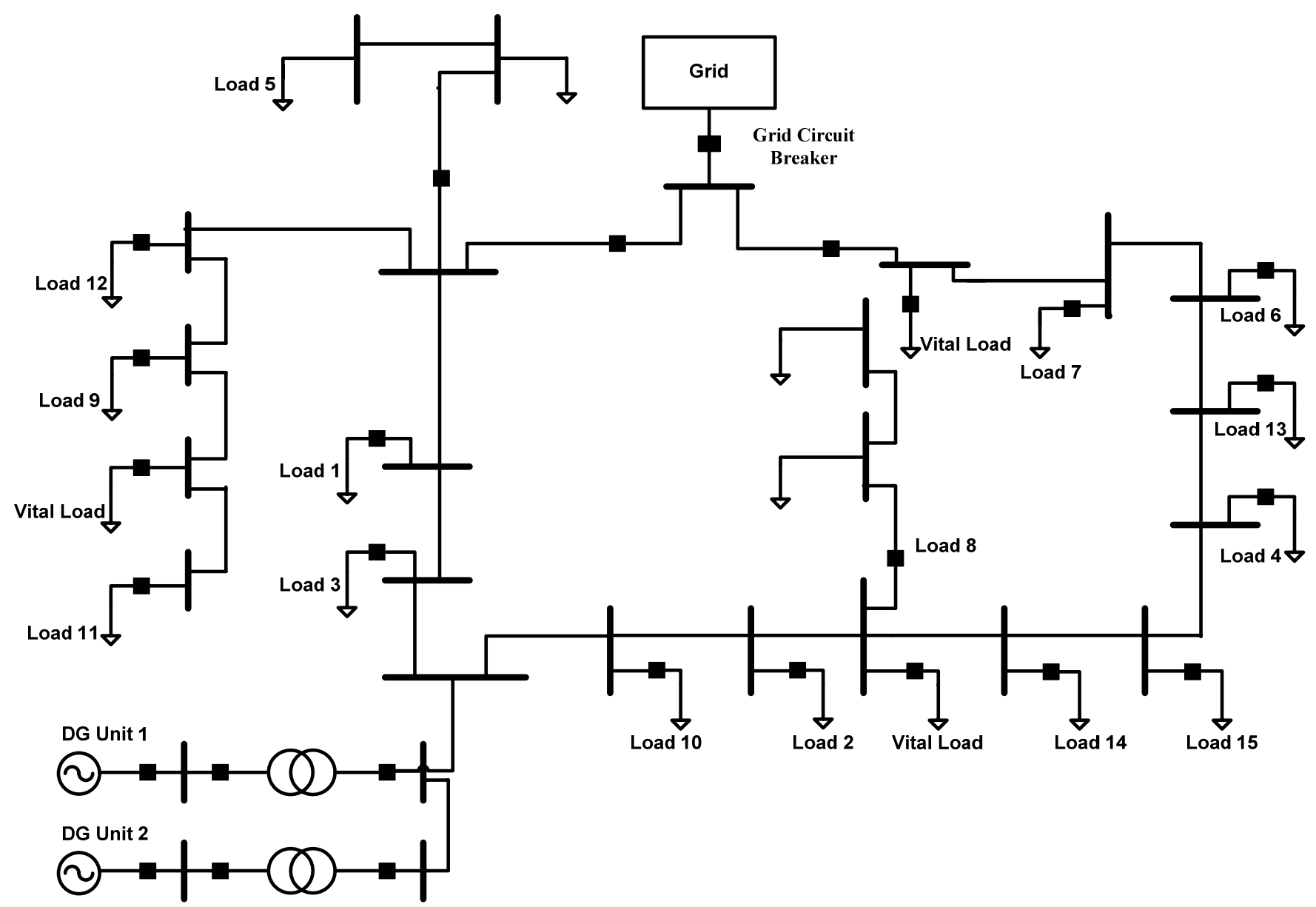

Figure 7. Test system

\section{Simulation Results}

\subsection{Case I: Islanding Operation}

To simulate the islanding operation case, the distribution network is assumed to operate at peak load capacity (3.66MW) and overload capacity of 4.3299MW. In this case, intentional islanding is applied at $t=5 \mathrm{~s}$. When grid is disconnected the FBLSM monitors the frequency and checks whether it crosses the $49.5 \mathrm{~Hz}$ limit. If frequency drops below $49.5 \mathrm{~Hz}$, FBLSM estimates the power imbalance and determines the amount of load to shed. Depending upon the amount, it trips number of load feeders to stabilize frequency. The behaviour of frequency for the both cases is shown in Figure 8 .

It can be noticed from Figure 8 that the in 3.66MW case, the mini hydro units are supplying 2.92MW and grid supplies 0.678MW. After grid is disconnected load shedding technique is activated and frequency drops to $48.27 \mathrm{~Hz}$, in this case 6 breakers are shed. However, in 4.2933MW, the power supplied by grid is $1.409 \mathrm{MW}$. In this case the frequency drops to $47.837 \mathrm{~Hz}$ and in this case 9 breakers are shed to stabilize the frequency. By applying proposed UFLS scheme the frequency recover to nominal value after some time. The power graph is shown in Figure 9

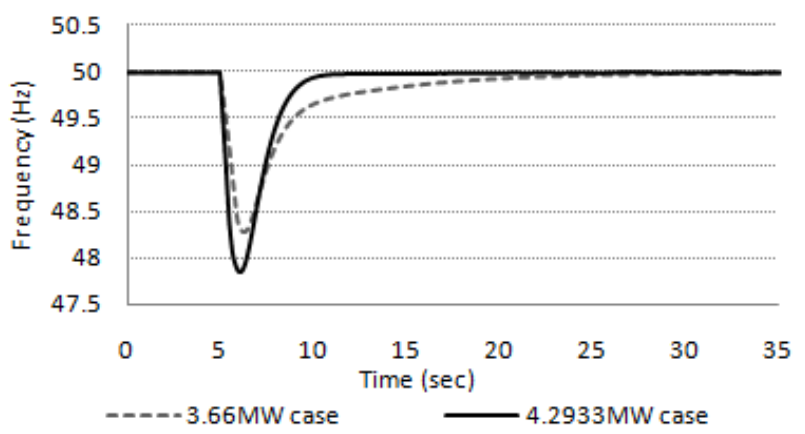

Figure 8. Frequency response during islanding operation

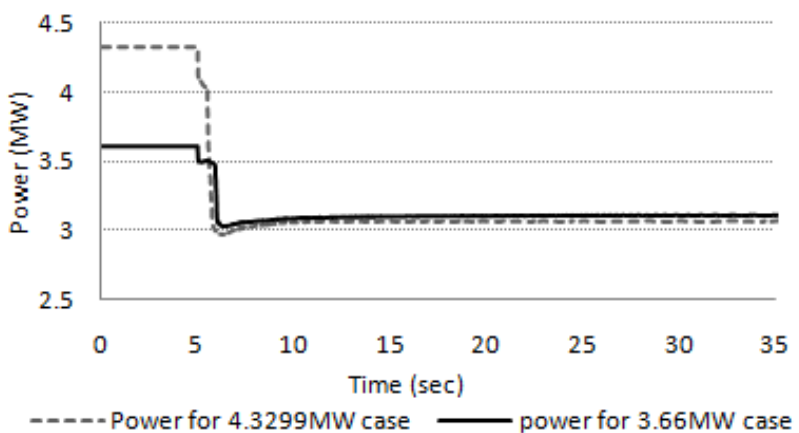

Figure 9. Power graph during islanding operation 


\subsection{Case II: Generator Tripping}

To simulate generator tripping case, one of the mini hydro unit is disconnected from islanded network at $t=5 \mathrm{~s}$. The distribution is operating at peak load capacity (3.66MW) at this moment. When generator is disconnected, load shedding strategy is operated to shed some load and stabilize the frequency. The behaviour of frequency during mini hydro unit tripping is shown in Figure 10.

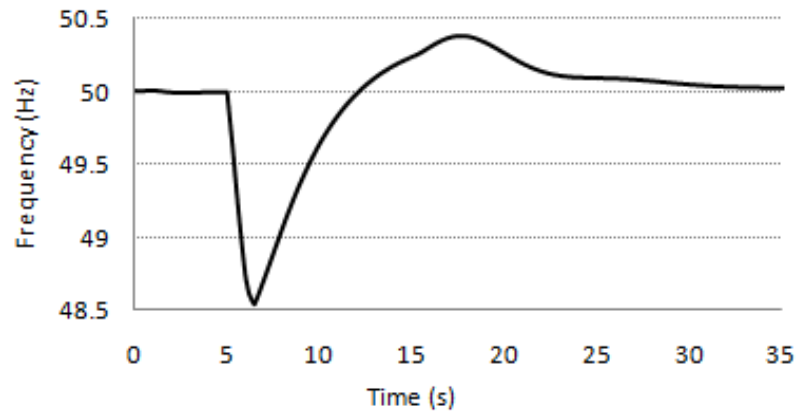

Figure 10. Frequency response at generator tripping

It can be noticed from Figure 10 that by applying proposed scheme, frequency drops to $48.56 \mathrm{~Hz}$ and recovered to $50 \mathrm{~Hz}$ after some time. In this case $11^{\text {th }}$ load ranked are shed. The power graph is shown in Figure 11.

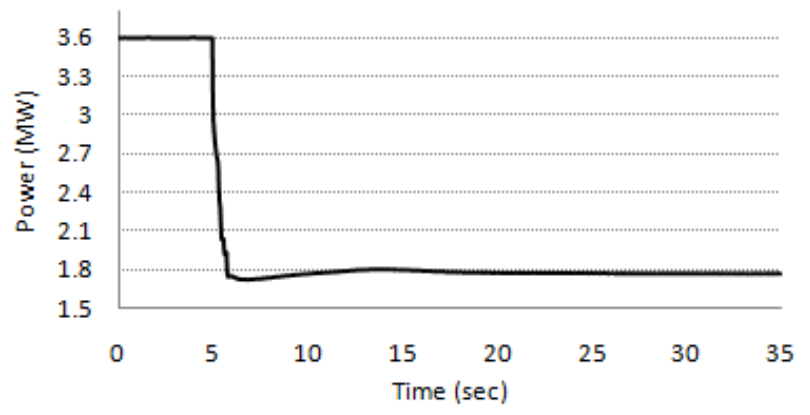

Figure 11. Power graph during generator tripping case

\section{Conclusion}

This paper has presented a new under frequency load shedding technique, suitable for islanding operation and generator tripping cases. The proposed load shedding technique is based on fuzzy based load shedding Module (FBLSM). The FBLSM determines the amount of power imbalance by measuring the frequency and rate of change of frequency. From the power imbalance, the correct amount of load is shed to stabilize the frequency. The proposed technique is tested for islanding operation and generator tripping case on a distribution network. The simulation results show that the proposed technique provides the satisfactory operation during islanding operation and generator tripping case. It can be concluded that proposed load shedding scheme successfully stabilizes the frequency by shedding optimal number of loads.

\section{Acknowledgement}

This work is supported by the Ministry of Higher Education (MOHE-ER025-2011A), University of Malaya and Quaid-e-Awam University of Engineering Science \& Technology Nawabshah, Sindh, Pakistan.

\section{References}

[1] Akash Davda, M. D. Desai, and B. R. Parekh, "Assessment of Reduction in Losses by Distributed Generation Penetration in a Radial Network: a Case Study," International Review on Modelling and Simulations (IREMOS), 4(1), 2011, 120-124.

[2] H. Mohamad, H. Mokhlis, A. H. A. Bakar, and H. W. Ping, "A review on islanding operation and control for distribution network connected with small hydro power plant," Renewable and Sustainable Energy Reviews, 15(8), 2011, 3952-3962.

[3] "IEEE Standard for Interconnecting Distributed Resources With Electric Power Systems," IEEE Std 15472003, 2003, 1-16.

[4] "IEEE Recommended Practice for Utility Interface of Photovoltaic (PV) Systems," IEEE Std 929-2000, 2000, i.

[5] X. Ding and A. A. Girgis, "Optimal load shedding strategy in power systems with distributed generation," in IEEE Power Engineering Society Winter Meeting, 2001, 788-793.

[6] V. V. Terzija and H. J. Koglin, "Adaptive underfrequency load shedding integrated with a frequency estimation numerical algorithm," Proc. Generation, Transmission and Distribution, 2002, 713-718.

[7] P. M. Anderson and M. Mirheydar, "An adaptive method for setting underfrequency load shedding relays," IEEE Transactions on Power Systems, 7(2), 1992, 647655.

[8] F. Shokooh, J. J. Dai, S. Shokooh, J. Tastet, H. Castro, T. Khandelwal, and G. Donner, "Intelligent Load Shedding," IEEE Industry Applications Magazine, 2011, 44-53.

[9] J. Jung, L. Chen-Ching, S. L. Tanimoto, and V. Vittal, "Adaptation in load shedding under vulnerable operating conditions," IEEE Transactions on Power Systems, 17(4), 2002, 1199-1205.

[10] A. A. Mohd Zin, H. Mohd Hafiz, and M. S. Aziz, "A review of under-frequency load shedding scheme on TNB system," Proc. Power and Energy Conference, PECon 2004, 170-174.

[11] M. Lukic, I. Kuzle, and S. Tesnjak, "An adaptive approach to setting underfrequency load shedding relays for an isolated power system with private generation," in 9th Mediterranean Electrotechnical Conference, MELECON, 1998, 1122-1125. 